\title{
Development of Three Dimensional Kinetic Monte Carlo (3D-KMC) Grain Growth Simulator Based on Tight Binding Quantum Chemical Molecular Dynamics and Its Application to the Analysis of Thermal Grain Growth of $\mathrm{CeO}_{2}$ and $\mathrm{Rh} / \mathrm{CeO}_{2}$
}

\author{
Ai SUZUKI*, Marc C. WILLIAMS, Kenji INABA, Ryo SATO, Kotaro OKUSHI, \\ Ryuji MIURA, Nozomu HATAKEYAMA and Akira MIYAMOTO
}

New Industry Creation Hatchery Center, Tohoku University, 6-6-10, Aramaki, Aoba-ku, Sendai 980-8579, Japan *e-mail:ai@aki.che.tohoku.ac.jp

(Received: June 27, 2012; Accepted for publication: September 13, 2012; Advance publication: November 10, 2012)

The electronic configuration between the interface of supported $\mathrm{Rh}$ and $\mathrm{CeO}_{2}$ (111) surface was investigated by Tight Binding based Ultra Accelerated Quantum Chemical Molecular Dynamics method (TB-UAQCMD) at 1073 K. Time courses of bond energies of Rh-O (-Ce) plots for $5000 \mathrm{fs}$ showed gradual increases of bond strength between oxygen and rhodium atoms in the uppersurface of the $\mathrm{CeO}_{2}$ (111). This caused the anchoring effect of $\mathrm{Rh}-\mathrm{O}$ (-Ce) bonds in the form of Rh-O (-Ce). Therefore total energies of the $\mathrm{Ce}-\mathrm{O}$ bonds in the $\mathrm{Rh} / \mathrm{CeO}_{2}$ were found to become more stable than that in the pure $\mathrm{CeO}_{2}$. The activation energy of grain growth of $\mathrm{Rh} / \mathrm{CeO}_{2}$ nanoparticles was estimated by this deviation in these $\mathrm{Ce}-\mathrm{O}$ bond energies. Experimentally observed suppression in the grain growth of $\mathrm{Rh} / \mathrm{CeO}_{2}$ nanoparticles relative to those without Rh was quantitatively reproduced by three dimensional Kinetic Monte Carlo method (3D-KMC).

Keywords: Tight-binding (TB), Ultra accelerated quantum chemical molecular dynamics (UA-QCMD), Three-dimensional Kinetic Monte Carlo (3D-KMC), $\mathrm{CeO}_{2}, \mathrm{Rh}$

\section{Introduction}

Ceria is widely used as a catalytic support with noble metals (Pt, $\mathrm{Pd}$ and $\mathrm{Rh}$ ) for oxygen reduction reaction of fuel cells and purification of vehicle exhaust gases. Especially for the combination of $\mathrm{Rh}-\mathrm{CeO}_{2}$, it is effective for the decomposition of $\mathrm{N}_{2} \mathrm{O}$ and methanol [1]. Several first-principle models to investigate interfaces between noble metals and $\mathrm{CeO}_{2}$ were presented by $\mathrm{B}$. $\mathrm{Li}$ [2] and $\mathrm{Z}$. Lu [3]. However, only a small number of atoms was composed in these cluster models for noble metals which have many orbitals including $4 \mathrm{~d}$ and $5 \mathrm{~d}$ due to large computational load. In addition, real supported noble metals, such as Pt and Rh were confirmed by Transmission Electron Microscopy (TEM) or High Resolution Transmission Electron
Microscopy (HRTEM) [4-7] to be exposed (111) facet on the $\mathrm{CeO}_{2}$ surface. In order to reflect the fact in the models for theoretical investigation, the supported Rh cluster was modeled by a larger number of atoms to form about $1 \mathrm{~nm}$ size. The state of $\mathrm{Rh}$ on $\mathrm{CeO}_{2}$ was quantum chemically investigated under realistic temperature, the same as the catalyst utilization temperature, at $1073 \mathrm{~K}$. The grain growths of pure $\mathrm{CeO}_{2}$ and $\mathrm{Rh} / \mathrm{CeO}_{2}$ also confirmed whether the three dimensional Kinetic Monte Carlo (3D-KMC) simulation can quantitatively reproduce experimental magnitude of grain growth. 


\section{Methodologies}

\subsection{Quantum chemical molecular dynam- ics}

Both "time" and "temperature" are essential factors for thermal durability of catalysts, and mobility and sinterability of catalysts are affected in the catalyst performance. However, it is not sufficient to depend only on conventional theoretical methodologies. They have individual shortcomings. For example, Static Monte Carlo methods cannot consider real-time scale. Molecular dynamics methods can consider temperature, but time scales in this method are too short to trace aging phenomenon since a real-time scale is needed in actual durability tests. $A b$ initio quantum chemical methodology can evaluate electronic properties with relatively high accuracy, but only with smaller cluster sized molecules due to its heavy computational load, it cannot be applied to the large atomic scale, nonetheless, thermal dynamics. For this situation, in order to trace a series of phenomena affecting catalyst durability and include physical mechanisms, we try to continuously reflect microscopic characteristics into macroscopic perspectives. This modeling concept can be achieved by performing simulations of multi-scale models with each model having different scales. The investigation in the nm-scale area, such as interface between supported Rh and $\mathrm{CeO}_{2}$ (111) facet was conducted by the ultra accelerated quantum chemical molecular dynamics (UA-QCMD) method. The results of UA-QCMD were introduced into the diffusion parameters which determine the diffusion of supports in particle based 3D-KMC method. It was applied to the simulation of grain growth of both $\mathrm{CeO}_{2}$ and $\mathrm{Rh}$ supported $\mathrm{CeO}_{2}$ nanoparticles. Both methods UA-QCMD and 3D-KMC considered temperature.

\subsection{Quantum chemical analysis}

Since $a b$ initio quantum chemical calculations are computationally intensive, it is very time consuming to perform the thermal dynamics simulations. This means that semi-empirical QM methods have to be employed. To achieve the required accura$\mathrm{cy}$, it is possible to use parameters, for example, the exponent of a Slater-Type atomic orbital (AO) and valence-state ionization potentials (VSIPs). By this technique, without heavy computational load, the UA-QCMD can calculate the electronic configuration to investigate the affinity of Rh catalyst on the surface of ceria support (111) facet under the temperature, $1073 \mathrm{~K}$. UA-QCMD has proved to be a very successful technique for a detailed understanding of diffusion or aggregation processes involving metal clusters, allowing us to explore cluster evolu- tion and understand the behavior of supported and unsupported metal clusters at the atomic level by reflecting binding energy and charges based on quantum calculations. The electronic configuration of catalysts was calculated after UA-QCMD simulation by original Tight Binding Quantum Chemical (TBQC) calculation.

Dynamics of atoms were carried out using the following potential functions, which were employed to consider the ionic, covalent interactions among atoms.

$$
\begin{aligned}
& U=\sum_{i} \sum_{j>1}\left[\frac{Z_{i} Z_{j} e^{2}}{R_{i j}}+f_{0}\left(b_{i}+b_{j}\right) \exp \left(\frac{a_{i}+a_{j}-R_{i j}}{b_{i}+b_{j}}\right)\right] \\
& +\sum_{i} \sum_{j>1} D_{i j}\left[\exp \left\{-2 \beta_{i j}\left(R_{i j}-R_{0}\right)\right\}-2 \exp \left\{-\beta_{i j}\left(R_{i j}-R_{0}\right)\right\}\right]
\end{aligned}
$$

The first term corresponds to the Coulomb potential, and the second term corresponds to the short-range exchange repulsion potential $\left(f_{0}\right.$ is the constant for unit adjustment, $a$ is the size, and $b$ is the stiffness), which gives a good account of the repulsive interactions arising from the overlap of electronic clouds. $Z_{i}$ and $Z_{i}$ are the charges of atoms, e is the elementary charge, and $R_{i j}$ is the internuclear distance. The third

term in eq. (1) corresponds to the Morse-type potential which represents covalent interactions, where $D_{i j}$ is the bond energy, $\beta_{i j}$ is the form factor, and $R_{0}$ is the bond length at minimum energy. Using the described potentials, a classical molecular dynamics (MD) simulation [8] was performed. This system can solve the equation of motion for large sets of atoms. In this MD simulator, a Verlet algorithm [9] is employed to integrate equations of motion. Moreover, the temperature scaling method was implemented in the system, which is similar to the Woodcock algorithm [10]. UA-QCMD simulations were carried out with a $0.1 \mathrm{fs}$ of integration time for the equations of motions.

Our UA-QCMD method consists of two parts. The first part is an TBQC calculation. The second part of our methodology involves the classical MD simulator [8]. To reflect the Morse-type function and the atomic charges into during the MD simulation process, TBQC calculations are performed at the beginning and after UA-QCMD simulation. In this method, an electronic structure calculation is performed by solving the Schrödinger equation $\mathbf{H C}={ }_{\varepsilon} \mathbf{S C}(\mathbf{H}, \mathbf{C}, \varepsilon$, and $\mathbf{S}$ refer to the Hamiltonian matrix, eigenvector, eigenvalues, and overlap integral matrix, respectively) with the diagonalization condition $\left(\mathbf{C}^{\mathrm{T}} \mathbf{S C}=\mathbf{I}\right.$; I refers to the identity matrix $)$. In order to determine the off-diagonal elements of $\mathbf{H}, H_{r s}$, the corrected distancedependent Wolfsberg-Helmholz formula, eq. (2) was used: 
Table 1. Coefficients of a single zeta parameters in a Slater-type atomic orbital in eq. (6)

\begin{tabular}{lcllllc}
\hline Element & AO & $\boldsymbol{s}_{\boldsymbol{0}}$ & $\boldsymbol{s}_{\boldsymbol{1}}$ & $\boldsymbol{s}_{\mathbf{2}}$ & $\boldsymbol{s}_{\mathbf{3}}$ & Coefficient \\
\hline $\mathrm{O}$ & $\mathrm{s}$ & 2.145 & 0.0802 & 0.0185 & 0.0007 & 1.0 \\
& $\mathrm{p}$ & 1.9664 & 0.5181 & 1.0817 & 1.1475 & 1.0 \\
$\mathrm{Rh}$ & $\mathrm{s}$ & 1.449 & 1.0 & 0.0 & 0.0 & 1.0 \\
& $\mathrm{p}$ & 1.50 & 1.0 & 0.0 & 0.0 & 1.0 \\
& $\mathrm{~d}$ & 2.939 & 1.0 & 0.0 & 0.0 & 1.0 \\
$\mathrm{Ce}$ & $\mathrm{s}$ & 1.9165 & 1.1446 & 0.0 & 0.0 & 1.0 \\
& $\mathrm{p}$ & 1.8592 & 1.9970 & 0.0 & 0.0 & 1.0 \\
& $\mathrm{~d}$ & 2.2319 & 1.1768 & 0.0 & 0.0 & 1.0 \\
& $\mathrm{f}$ & 3.0582 & 1.3363 & 0.0 & 0.0 & 1.0 \\
\hline
\end{tabular}

$$
H_{r s}=\frac{K}{2} S_{r s}\left(H_{r r}+H_{s s}\right)
$$

In the TBQC scheme, the total energy of a system, $E$ is expressed by using the following equation,

$$
\begin{aligned}
E= & \sum_{k=1}^{o c c} n_{k} \varepsilon_{k}+\sum_{i} \sum_{j>1} \frac{Z_{i} Z_{j} e^{2}}{R_{i j}} \\
& +\sum_{i} \sum_{j>1}\left(b_{i}+b_{j}\right) \exp \left(\frac{a_{i}+a_{j}-r_{i j}}{b_{i}+b_{j}}\right)
\end{aligned}
$$

Summing up the values of $b_{i}, b_{j}$ and $a_{i}, a_{j}$, we can modify the eq. (3) as follows;

$$
E=\sum_{k=1}^{o c c} n_{k} \varepsilon_{k}+\sum_{i} \sum_{j>1} \frac{Z_{i} Z_{j} e^{2}}{R_{i j}}+\sum_{i} \sum_{j>1} b_{i j} \exp \left(\frac{a_{i j}-R_{i j}}{b_{i j}}\right)
$$

where the first, second, and third terms on the right-hand side refer to the molecular orbital (MO) energy, Coulombic energy, and exchange-repulsion energy, respectively. The first term on the right-hand side of eq. (4) is rewritten as follows:

$$
\begin{aligned}
\sum_{k=1}^{o c c} n_{k} \varepsilon_{k} & =\sum_{k=1}^{o c c} \sum_{r} n_{k}\left(C_{k r}\right)^{2} H_{r r} \\
& +\sum_{k=1}^{o c c} \sum_{r} \sum_{s} n_{k} C_{k r} C_{k s} H_{r s}
\end{aligned}
$$

where the first and second terms on the right-hand side refer to the one-electron contribution to the binding energy and the twoelectrons contributions to the binding energy, respectively $\left(n_{k}\right.$ is the number of electrons in the $k$-th molecular orbital). A binding energy calculated from the second term of eq. (5) is used for the determination of the $D_{\mathrm{ij}}$ parameter in eq. (1).

In order to set the Hamiltonian matrix, $\mathbf{H}$ and overlap integral matrix, $\mathbf{S}$ in the TBQC scheme, exponents of a Slater-type AO, denoted as $\zeta_{\mathrm{r}}$, and VSIPs for the valence shell of calculation atoms must be optimized. The former parameters are used to calculate the $\mathbf{S}$ matrix and $H_{r s}$ in eq. (2). The latter ones are used for the diagonal element of $\mathbf{H}\left(H_{r r}\right.$ or $H_{s S}$ in eq. (2)).

The relationship between $H_{r r}$ and VSIP of the r-th AO of the i-th atom $\left(I_{r}^{i}\right)$ is described as, $H_{r r}=-I_{r}^{i}$. These two parameters in the TBQC scheme, were represented by the polynomial functions of atomic charges. The $\zeta_{\mathrm{r}}$ and $H_{r r}$ were calculated by the polynomial functions of atomic charges described below by eq. (6) and (7), respectively.

$$
\zeta_{r}=s_{0}+\sum_{k=1}^{3} s_{k}\left(Z_{i}\right)^{k}
$$

$$
H_{r r}=h_{0}+\sum_{k=1}^{4} h_{k}\left(Z_{i}\right)^{k}
$$

In eq. (6) and eq. (7), $Z_{i}$ corresponds to the atomic charge on atom $i$. The parameters regarding $\zeta_{\mathrm{r}}$, i.e., $s_{0}, s_{1}, s_{2}$ and $s_{3}$ in eq. (6), and those regarding $H_{r r}$, i.e., $h_{0}, h_{1}, h_{2}, h_{3}, h_{3}$ and $h_{4}$ in eq. (7), were adjusted to reproduce the binding energies and electronic structures of each reactant obtained by first principles calculations; these are summarized in Tables 1 and 2, respectively.

\subsection{D-KMC method}

Diffusion of supported nanoparticles as well as support particles was simulated by an originally developed 3D-KMC program [11]. In this study, the program named SINTA polygon was applied to simulate the grain growth process of the polygon shaped model. A schematic flowchart of the 3D-KMC algorithm of grain growth of ceria support was added as Figure 6. As shown in Figure 6, it was enabled by repeating a series of events for the involved number of nanoparticles in the supports with a determined number of steps. The coordinates output by the system are then used to map the process of the grain growth of $\mathrm{Rh} / \mathrm{CeO}_{2}$ nanoparticles. This enables comparison of the characteristics of the grain growth process of $\mathrm{CeO}_{2}$ support nanoparticles with experimental results. During the simulation a diffusion direction is randomly generated while the diffusion 
Table 2. Coefficients of the $H_{r r}$ parameters in eq. (7)

\begin{tabular}{lcccccl}
\hline Element & AO & $\boldsymbol{h}_{\boldsymbol{0}}$ & $\boldsymbol{h}_{\boldsymbol{1}}$ & $\boldsymbol{h}_{\mathbf{2}}$ & $\boldsymbol{h}_{\mathbf{3}}$ & $\boldsymbol{h}_{\boldsymbol{4}}$ \\
\hline $\mathrm{O}$ & $\mathrm{s}$ & -28.6066 & -15.0328 & -1.4510 & -0.4949 & 0.0419 \\
$\mathrm{Rh}$ & $\mathrm{p}$ & -14.2851 & -14.8159 & -1.6244 & 0.0154 & 0.0434 \\
& $\mathrm{~s}$ & -8.0526 & -4.40 & 0.0 & 0.0 & 0.0 \\
& $\mathrm{p}$ & -3.5500 & -0.50 & 0.0 & 0.0 & 0.0 \\
$\mathrm{Ce}$ & $\mathrm{d}$ & -8.4292 & -7.60 & 0.0 & 0.0 & 0.0 \\
& $\mathrm{~s}$ & -6.2303 & -1.4425 & 0.0 & 0.0 & 0.0 \\
& $\mathrm{p}$ & -1.5612 & -0.0986 & 0.0 & 0.0 & 0.0 \\
& $\mathrm{~d}$ & -8.0356 & -2.7249 & 0.0 & 0.0 & 0.0 \\
& $\mathrm{f}$ & -8.7929 & -2.8099 & 0.0 & 0.0 & 0.0 \\
\hline
\end{tabular}

Table 3. Energy validation for quantum chemically calculated total binding energies of cluster model of Rh55. The calculated energy by TB-QC was compared with experimental total energies [13].

\begin{tabular}{lccc}
\hline Element & TB-QC & Experiment & TB-QC/Experiment \\
\hline Rh55 & -7512.99 & -7320.60 & 1.02 \\
\hline
\end{tabular}

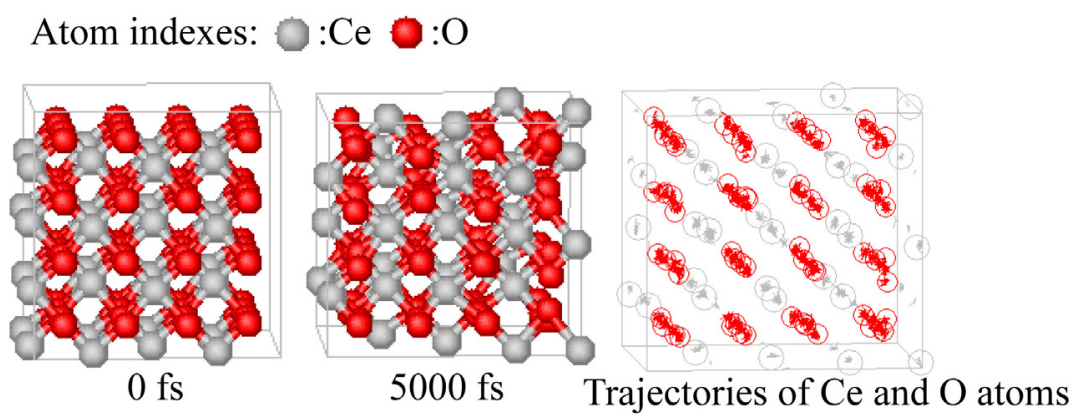

Figure 1. Snapshot of the results of UA-QCMD simulation at $1073.15 \mathrm{~K}_{\text {of }} \mathrm{CeO}_{2}$ periodical model and its atomic trajectories

length for one 3D-KMC step, $l$, is calculated as $l=\sqrt{D(r) \Delta t}$, where $D(r)$ and $\Delta t$ are the diffusion coefficient given as a function of particle size and the real-scale diffusion time per one 3D-KMC step, respectively. At the initial stage of grain growth, both metals and oxygens in the metal oxide can diffuse, meet and nucleate into larger atomic islands.

$$
D_{S}(r)=D_{S 0}\left(2 r_{S}\right)^{-n} \exp \left(-\frac{E_{S}}{R T}\right)
$$

$T, R$ and $n$ denote the absolute temperature, the gas constant, and particle size dependent coefficient of diffusion of supports, respectively. $D_{S 0}$ denotes the pre-factor of diffusion coefficient of the support. The nanoparticle size of the $\mathrm{CeO}_{2}$ support in the unit of $\mathrm{m}, r_{S}$ at a certain time was reflected into eq. (8) and $n=$ 1.0. The diffusion coefficients of $\mathrm{CeO}_{2}$ support in eq. (8) were determined as $D_{S 0}=35 \mathrm{~m}^{2} / \mathrm{s}$ and $E_{S}=458 \mathrm{~kJ} / \mathrm{mol}$ [12] based on experimental data [12].

\section{Results and Discussion}

\section{1 $\mathrm{CeO}_{2}(111)$ surface with and without Rh}

Experimentally estimated enthalpy of $\mathrm{Rh}_{55}$ [13] for supported metal cluster model as shown in the state in 0 fs of Figure 3 (a) at $298 \mathrm{~K}$ was $-7320.6 \mathrm{kcal} / \mathrm{mol}$ as noted in Table 3 . Total binding energy obtained by Tight Binding quantum chemical calculation was $-7512.99 \mathrm{kcal} / \mathrm{mol}$ for $\mathrm{Rh}_{55}$. This calculated energy was found to closely agree with experimentally measured enthalpies and determined parameters for eq. (6) and (7) were energetically validated. Figure 1 shows two snapshots of the structures of UA-QCMD simulation from 0 fs to 5000 fs with the atomic trajectories of ceriums and oxygens at $1073.15 \mathrm{~K}$ of $\mathrm{CeO}_{2}$. This calculation was conducted under the NPT ensemble (The pressure is $101.325 \mathrm{kPa}$, atmospheric pressure) with the time step of $1.0 \mathrm{fs} / \mathrm{step}$. The size of the $\mathrm{CeO}_{2}$ model was $\mathrm{x}=1.988 \mathrm{~nm}$ and $\mathrm{y}=1.91 \mathrm{~nm}$ under the periodic boundary condition. The $\mathrm{CeO}_{2}$ crystal structure maintained its structure at 


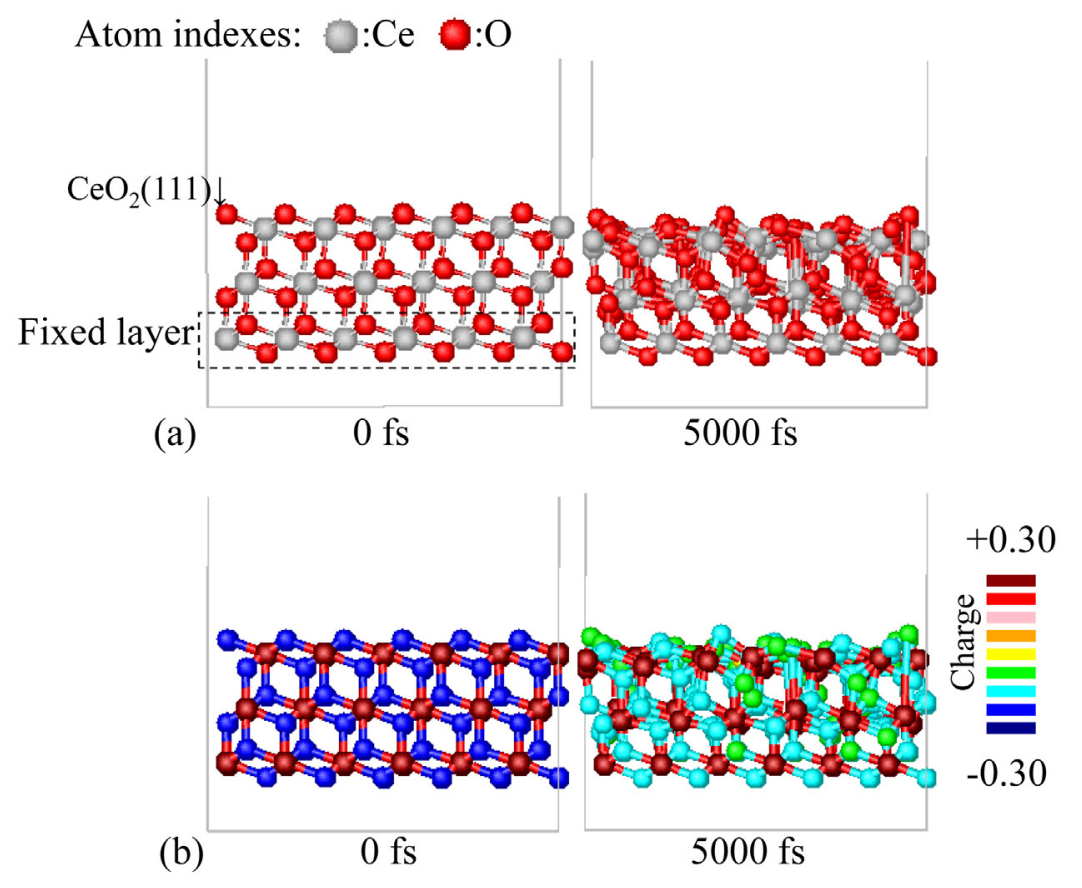

Figure 2. Snapshot of the results of UA-QCMD simulation at $1073.15 \mathrm{~K}$ (a) $\mathrm{CeO}_{2}(111)$ facet and (b) its electronic configuration.

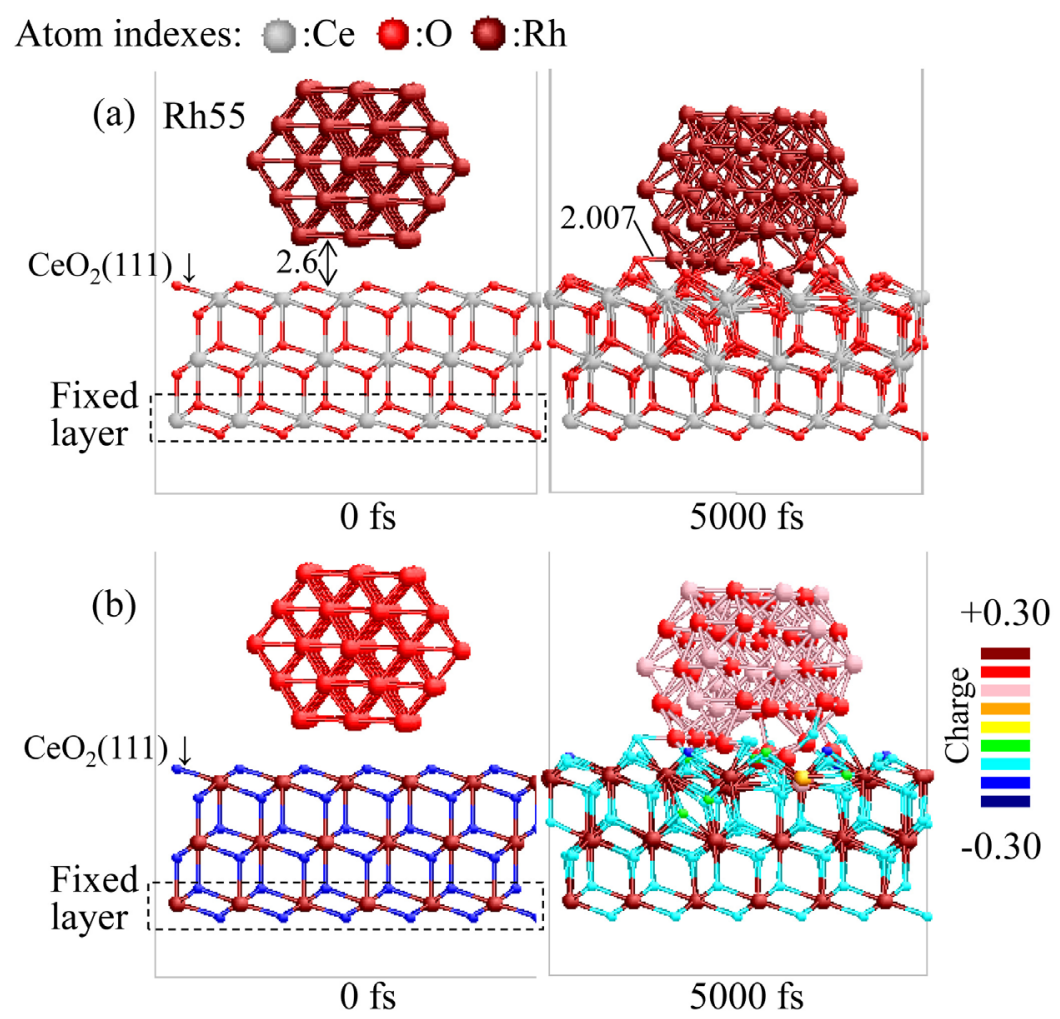

Figure 3. Snapshot of the results of UA-QCMD simulation at $1073.15 \mathrm{~K}$ (a) $\mathrm{Rh} 55 / \mathrm{CeO}_{2}(111)$ and (b) its electronic configuration. Numerical values are bond lengths in the unit of $\AA$. 


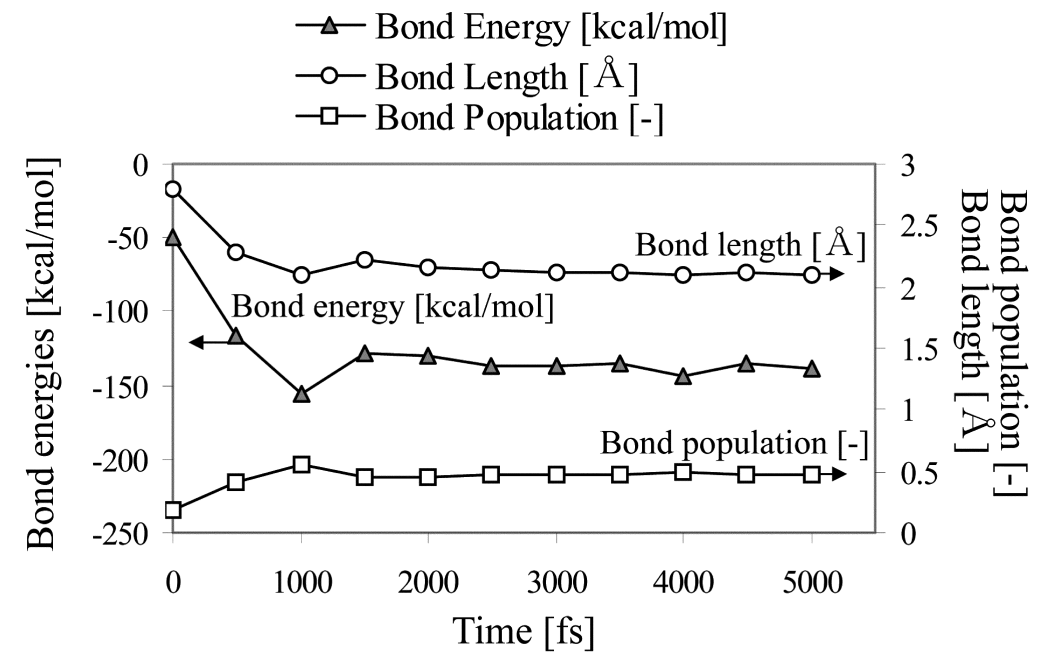

Figure 4. Time course of Rh-O bond energies, bond population and bond length obtained from UA-QCMD simulation at $1073.15 \mathrm{~K}$.

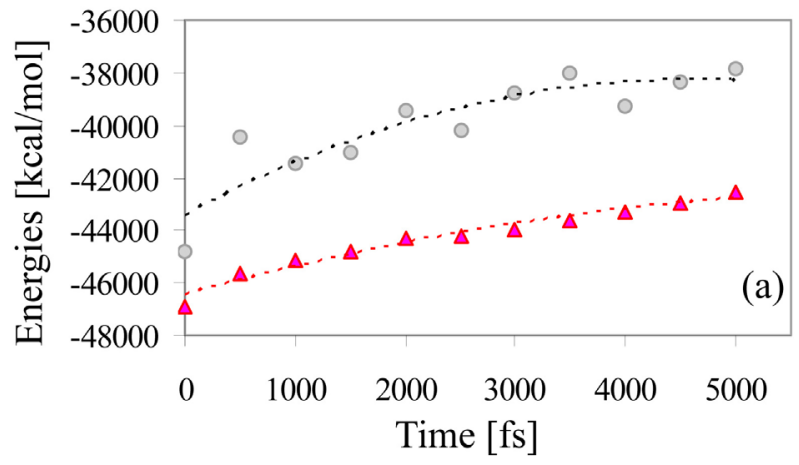

- $\mathrm{CeO} 2(111)$

$\Delta \quad \mathrm{Rh} / \mathrm{CeO} 2(111)$

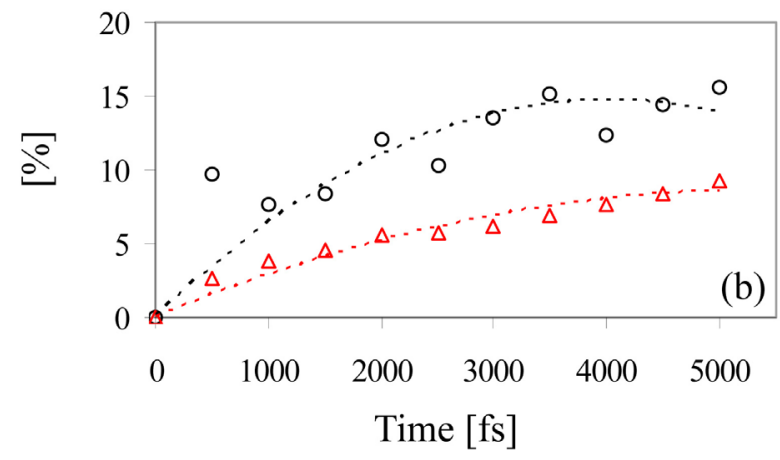

- $\mathrm{CeO} 2(111)$

$\Delta \quad \mathrm{Rh} / \mathrm{CeO} 2(111)$

Figure 5. Time course of total energies of $\mathrm{Ce}-\mathrm{O}$ all bonds in $\mathrm{CeO}_{2}$ obtained from UA-QCMD simulation at $1073.15 \mathrm{~K}$.

(a) Total energies of $\mathrm{Ce}-\mathrm{O}$ bonds in $\mathrm{CeO}_{2}(111)$ and $\mathrm{Rh} 55 / \mathrm{CeO}_{2}(111)$.

(b) Deviation percentage of $\mathrm{Ce}-\mathrm{O}$ bonds in $\mathrm{CeO}_{2}(111)$ and $\mathrm{Rh} 55 / \mathrm{CeO}_{2}(111)$.

$1073 \mathrm{~K}$ by determined parameters as shown in Tables 1 and 2 for eq. (6) and (7). Figure 2 (a) shows the snapshots of $\mathrm{CeO}_{2}$ (111) surface from 0 fs to 5000 fs obtained by UA-QCMD simulation at $1073 \mathrm{~K}$. Figure 2 (b) shows its electronic configuration. The calculation condition was the same as for the calculation shown in Figure 1. The oxygen and cerium atoms composed of oxygen termination $\mathrm{O}-\mathrm{Ce}-\mathrm{O}$ bonds in the uppermost layer were drastically moved. On the other hand, Figures 3 (a) and (b) show the snapshots of the $\mathrm{Rh}_{55} / \mathrm{CeO}_{2}$ (111) structures from 0 fs to $5000 \mathrm{fs}$ with electronic configurations obtained by UA-QCMD simulation. The size of $\mathrm{Rh}_{55} / \mathrm{CeO}_{2}$ model was $\mathrm{x}=1.988 \mathrm{~nm}$ and $\mathrm{y}=1.91 \mathrm{~nm}$ under the periodic boundary condition. The initial 


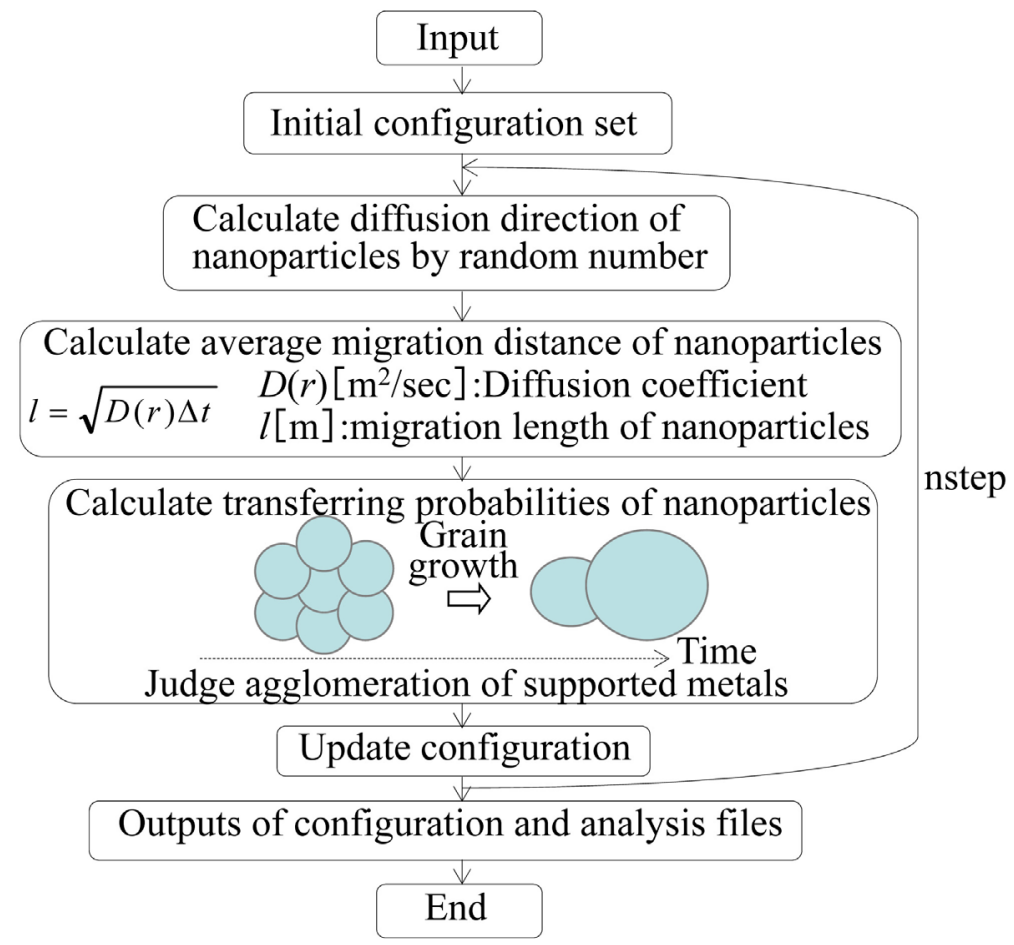

Figure 6. Algorithm of grain growth of nanoparticles

position of $\mathrm{Rh}_{55}$ cluster was more than $2.6 \AA$ from the upper surface of the $\mathrm{CeO}_{2}$ (111) surface. A snapshot after $5000 \mathrm{fs}$ in Figure 3 (a) gave a sample of penetration of a part of the $\mathrm{Rh}$ into the ceria which confirmed S. Imamura's experiment [1]. In Figure 4, time courses of Rh-O bond energies, bond population and bond length obtained from UA-QCMD simulation at 1073.15 K were shown. A solid triangle shows average bond energy of Rh-O, and its value became gradually larger from $-50 \mathrm{kcal} / \mathrm{mol}$ at $0 \mathrm{fs}$ to $-130 \mathrm{kcal} / \mathrm{mol}$ at $5000 \mathrm{fs}$. Open circle shows the length between $\mathrm{Rh}$ and $\mathrm{O}$, and its value became gradually closer to $2.8 \AA$ (A Rh55 cluster was far enough apart from the top of $\mathrm{CeO}_{2}$ surface) at $0 \mathrm{fs}$ to $2.0 \AA$ at $5000 \mathrm{fs}$. Open square shows bond population of Rh-O, and its value became gradually larger from 0.18 at 0 fs to 0.48 at 5000 fs. After 5000 fs, the bond length of Rh-O (-Ce) was about $2.0 \AA$. The bonding strength of Rh-O $(-\mathrm{Ce})(-130 \mathrm{kcal} / \mathrm{mol})$ is much greater than either Rh-Rh $(-27.75 \mathrm{kcal} / \mathrm{mol})$ or $\mathrm{Ce}-\mathrm{O}(-67 \mathrm{kcal} / \mathrm{mol})$. Thus the stable $\mathrm{Rh}-\mathrm{O}-\mathrm{Ce}$ bond structure was formed.

Next, the thermal diffusion of oxygen and cerium atoms to compose O-Ce-O bonds in the uppermost surface of $\mathrm{CeO}_{2}$ (111) surface was investigated. Additionally, the degree to which energetical stability was provided was investigated as Figure 5 (a) and (b). Figure 5 (a) shows the difference in total energies of all $\mathrm{Ce}-\mathrm{O}$ bonds in pure $\mathrm{CeO}_{2}(111)$ and $\mathrm{Rh} / \mathrm{CeO}_{2}$ (111) from 0 fs to $5000 \mathrm{fs}$. These results were obtained from the UA-QCMD simulations as shown in Figures 2 and 3. As shown in Figure 5 (b), total energies of $\mathrm{Ce}-\mathrm{O}$ bonds in $\mathrm{Rh} / \mathrm{CeO}_{2}$ were stabilized about 7-8\% compared with pure $\mathrm{CeO}_{2}$.

\subsection{Grain growth of $\mathrm{CeO}_{2}$ with and with- out Rh}

In order to demonstrate the particle based phenomena based on the nano-scale characteristics, 3D-KMC simulation was conducted. The $E_{s}$ in eq. (8) for $\mathrm{Rh} / \mathrm{CeO}_{2}$ was estimated as eq. (9);

$$
E_{s}=E_{s\left(\mathrm{CeO}_{2}\right)}+E_{s\left(\mathrm{CeO}_{2}\right)} \times \frac{E\left(\mathrm{Rh} / \mathrm{CeO}_{2}\right)-E\left(\mathrm{CeO}_{2}\right)}{E\left(\mathrm{CeO}_{2}\right)}
$$

Here, $\mathrm{E}\left(\mathrm{CeO}_{2}\right)$ and $\mathrm{E}\left(\mathrm{Rh} / \mathrm{CeO}_{2}\right)$ corresponds to total energies of all $\mathrm{Ce}-\mathrm{O}$ bonds in $\mathrm{CeO}_{2}(111)$ and $\mathrm{Rh} 55 / \mathrm{CeO}_{2}(111)$ surface, respectively in UA-QCMD simulations. The $E_{S}$ for $\mathrm{Rh} / \mathrm{CeO}_{2}$ was estimated as $505 \mathrm{~kJ} / \mathrm{mol}$ derived from the UAQCMD calculation result shown in Figure 2 and 3.

S. Sato and K. Tomishige [14] found by TEM micrograph that the shape of calcined $\mathrm{CeO}_{2}$ particles up to $1000^{\circ} \mathrm{C}$ was flat and smooth with exposing many stable (111) facets. Z. L. Wang and $\mathrm{X}$. Feng found that the evolution of $\mathrm{CeO}_{2}$ nanoparticle shapes proceeded from truncated octahedral to octahedral with exposing (111) facets [15]. It turns out that there are 14 and 8 facets for truncated octahedral and octahedral shapes, respec- 


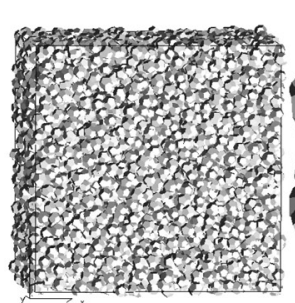

0 hour

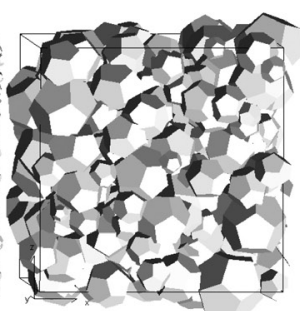

1 hour

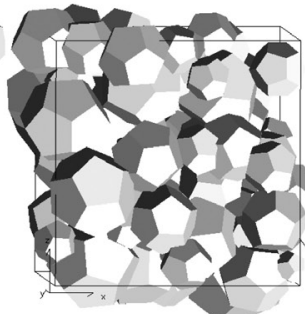

2 hours

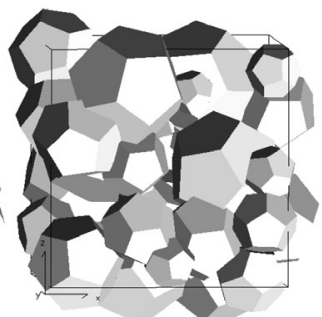

3 hours

Figure 7. Time evolution of grain growth process of $\mathrm{CeO}_{2}$ nanoparticles which have dodecahedral facets at $1073 \mathrm{~K}$ estimated by 3D-KMC simulation.

The model size is $\mathrm{x}=0.1 \mu \mathrm{m}, \mathrm{y}=0.1 \mu \mathrm{m}$ and $\mathrm{z}=0.1 \mu \mathrm{m}$.
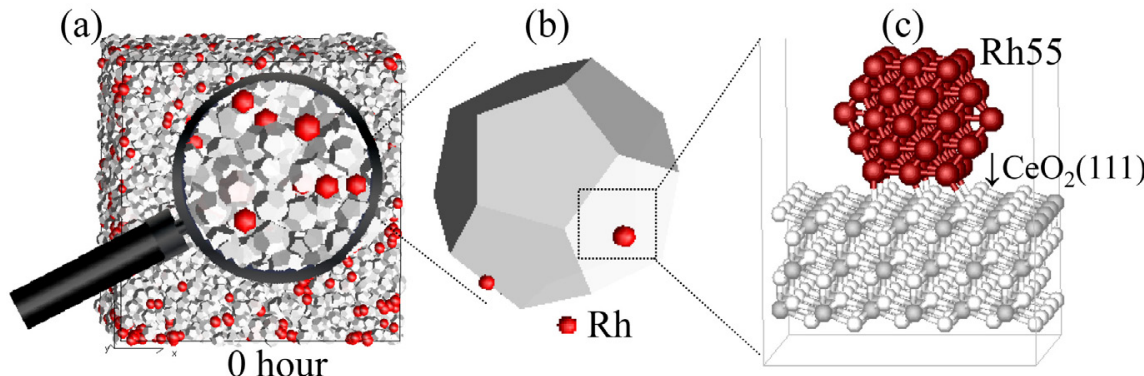

(d)
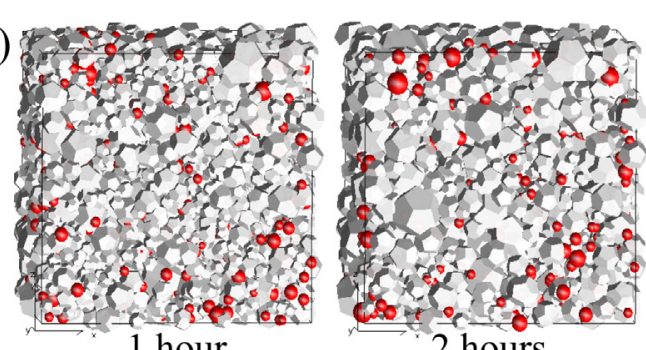

2 hours

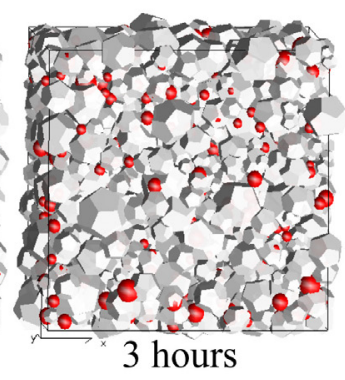

Figure 8. The model of thermal grain growth simulation of $5 \mathrm{wt} . \% \mathrm{Rh} / \mathrm{CeO}_{2}$ nano particles

(a) Particle based periodic boundary condition model for 3D-KMC simulation.

The model size is $\mathrm{x}=0.1 \mu \mathrm{m}, \mathrm{y}=0.1 \mu \mathrm{m}$ and $\mathrm{z}=0.1 \mu \mathrm{m}$.

(b) Enlarged illustration of supported noble metals on dodecahedral facets of particle based model

(c) Supported noble metal cluster on $\mathrm{CeO}_{2}(111)$ facet on periodic boundary condition.

(d) Time evolution of grain growth of $5 \mathrm{wt} . \% \mathrm{Rh} / \mathrm{CeO}_{2}$ nanoparticles at $1073 \mathrm{~K}$.

tively. K. Kaneko also found that $\mathrm{CeO}_{2}$ nanocrystals were truncated at the corners exposing (111) octahedral facets and at the edges (220) dodecahedral facets [16]. Therefore $\mathrm{CeO}_{2}$ nanoparticles were modeled dodecahedral facets which means facet number of 14 and 8 facets in order to agree with TEM results as mentioned above. A nanoparticle $\mathrm{CeO}_{2}$ model $(\mathrm{x}=0.1 \mu \mathrm{m}$, $\mathrm{y}=0.1 \mu \mathrm{m}$ and $\mathrm{z}=0.1 \mu \mathrm{m}$ ) has dodecahedral facets as shown in Figure 7 and 8. P. Bera confirmed that the average sizes of $\mathrm{CeO}_{2}$ crystallites are in the range of $25-35 \mathrm{~nm}$ [17]. Therefore the sizes of nanoparticles were set about $25 \mathrm{~nm}$. Figure 7 shows the time evolution of grain growth of $\mathrm{CeO}_{2}$ nanoparticles at $1073 \mathrm{~K}$ obtained by 3D-KMC simulation. O. Pozdnyakova found that most of the ceria particles were in the form of $\mathrm{CeO}_{2}$ (fluorite structure) with (110), (111) and (001) orientation [18]. N. Ichikawa and $\mathrm{S}$. Sato found that the (111) facet is predominant on large $\mathrm{CeO}_{2}$ particles, whereas the (100) and (110) facets are exposed on small particles [19]. N. Zouvelou estimated that the stability of orientaion of particles was of the following order; $(111)>(110)>(100)$ [11]. Therefore a Rh cluster was supported on $\mathrm{CeO}_{2}$ (111) facet as shown in Figure 3 and Figure 8 (c). Figure 8 (a) shows the model of thermal grain growth simulation for 5 wt. $\% \mathrm{Rh} / \mathrm{CeO}_{2}$ nanoparticles. The density of $\mathrm{Rh}$ is 


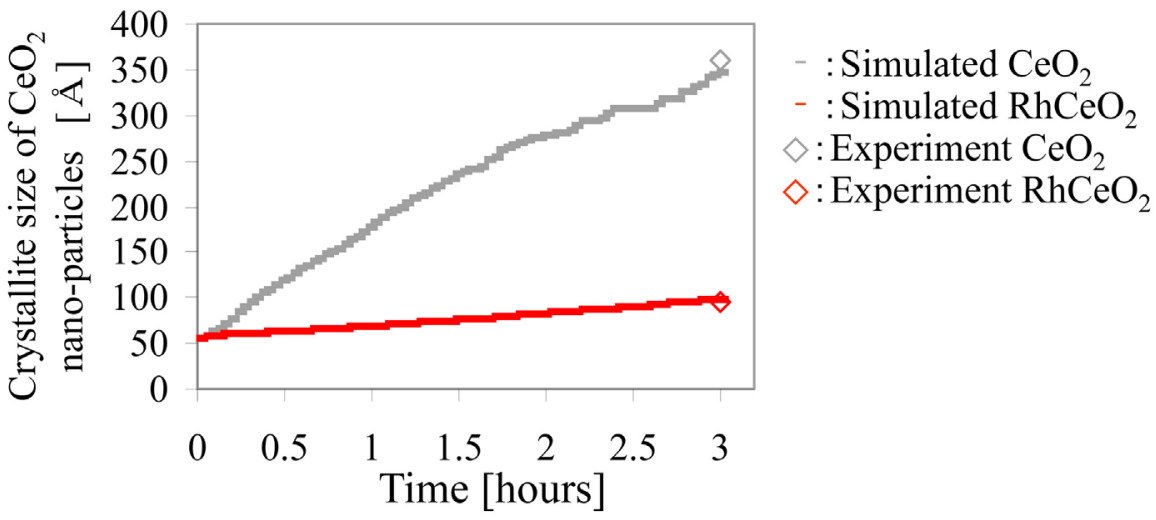

Figure 9. Time-course of agglomerated crystallite size of $\mathrm{CeO}_{2}$ and $\mathrm{Rh} / \mathrm{CeO}_{2}$ at $1073 \mathrm{~K}$ by $3 \mathrm{D}-\mathrm{KMC}$ simulation based on the result of UA-QCMD.

$12.41 \mathrm{~g} / \mathrm{cc}$. A nanoparticle $\mathrm{Rh} / \mathrm{CeO}_{2}$ model was set to be $\mathrm{x}=0.1$ $\mu \mathrm{m}, \mathrm{y}=0.1 \mu \mathrm{m}$ and $\mathrm{z}=0.1 \mu \mathrm{m}$. Rh nanoparticles were supported on flat and smooth $\mathrm{CeO}_{2}$ surfaces as shown in Figure 8 (b). Figure 8 (d) shows the grain growth of $\mathrm{Rh} / \mathrm{CeO}_{2}$ at $1073 \mathrm{~K}$ every hour for $3 \mathrm{~h}$ simulated by 3D-KMC. Simulated grain growth for $3 \mathrm{~h}$ at $1073 \mathrm{~K}$ for pure $\mathrm{CeO}_{2}$ was increased to $346.5 \AA$. Whereas that of $\mathrm{Rh} / \mathrm{CeO}_{2}$ was increased no further than $100 \AA$. These simulated results agreed with the quantitatively experimental results that $\mathrm{S}$. Hosokawa found that the $\mathrm{Rh}$ supported $\mathrm{CeO}_{2}$ had suppressed grain growth compared to pure $\mathrm{CeO}_{2}$ [20]. As shown in Figure 9, the experimentally measured crystallite size was $360 \AA$ for pure $\mathrm{CeO}_{2}$ calcined at $1073 \mathrm{~K}$ for $3 \mathrm{~h}$. This was much larger than the size of $\mathrm{CeO}_{2}$ supported with $\mathrm{Rh}, 95 \AA$.

\section{Conclusion}

The formation of Rh-O-Ce bonds is the key factor which caused the difference in the magnitude of grain growth between $\mathrm{CeO}_{2}$ and $\mathrm{Rh} / \mathrm{CeO}_{2}$. Bond population, bond length and bond energy of Rh-O obtained from UA-QCMD simulations at $1073 \mathrm{~K}$ showed the formation of $\mathrm{Rh}-\mathrm{O}$ (-Ce) bonds in the upper surfaces of $\mathrm{CeO}_{2}$ (111). This was caused by anchoring of $\mathrm{Rh}$ atoms through $\mathrm{Rh}-\mathrm{O}-\mathrm{Ce}$ bonds on the $\mathrm{CeO}_{2}$ support. This caused the energetic difference of $\mathrm{Ce}-\mathrm{O}$ bonds in the $\mathrm{CeO}_{2}$ surfaces with and without $\mathrm{Rh}$. It could reflect into the $3 \mathrm{D}-\mathrm{KMC}$ simulation as the diffusion parameters. By introducing quantum chemical characteristics into the 3D-KMC method, experimentally observed suppression of grain growth in $\mathrm{Rh} / \mathrm{CeO}_{2}$ relative to pure $\mathrm{CeO}_{2}$ could be quantitatively reproduced.

\section{References}

[1] S. Imamura, T. Yamashita, R. Hamada, Y. Saito, Y. Nakao, N. Tsuda, C. Kaito, J. Mol. Catal. A: Chemical, 129, 249 (1998). [CrossRef]

[2] B. Li, O. K. Ezekoye, Q. Zhang, L. Chen, P. Cui, G. Graham, X. Pan, Phys. Rev. B, 82, 125422 (2010). [CrossRef]

[3] Z. Lu, Z. Yang, J. Phys. Condens. Matter., 22, 475003 (2010). [Medline] [CrossRef]

[4] S. Bernal, J. J. Calvino, J. M. Gatica, C. Larese, C. L ópez-Cartes, J. A. P érez-Omil, J. Catal, 169, 510 (1997). [CrossRef]

[5] S. Bernal, G. Blanco, J. J. Calvino, J. M. Gatica, J. A. Perez Omil, J. M. Pintado, Top. Catal., 28, 31 (2004). [CrossRef]

[6] S. Bernal, J. J. Calvino, M. A. Cauqui, J. M. Gatica, C. López Cartes, J. A. Pérez Omil, J. M. Pintado, Catal. Today, 77, 385 (2003). [CrossRef]

[7] S. Bernal, J. J. Calvino, M. A. Cauqui, J. M. Gatica, C. López Cartes, J. A. Pérez Omil, J. M. Pintado, Catal. Today, 23, 219 (1995). [CrossRef]

[8] P. Selvam, H. Tsuboi, M. Koyama, A. Endou, H. Takaba, M. Kubo, C. A. DelCarpio, A. Miyamoto, Rev. Chem. Eng, 22, 377 (2006). [CrossRef]

[9] L. Verlet, Phys. Rev, 159, 98 (1967). [CrossRef]

[10] L. V. Woodcock, Chem. Phys. Lett, 10, 257 (1971). [CrossRef]

[11] A. Suzuki, K. Nakamura, R. Sato, K. Okushi, R. Miura, R. Nagumo, H. Tsuboi, N. Hatakeyama, A. Endou, H. Takaba, M. C. Williams, A. Miyamoto, Surf. Sci, 603, 3049 (2009). [CrossRef]

[12] N. Zouvelou, X. Mantzouris, P. Nikolopoulos, Materials 
Science \& Engineering A, 495, 54 (2008). [CrossRef]

[13] W. M. Haynes, CRC Handbook of Chemistry and Phys$i c s, 91^{\text {st }}$ ed., CRC press, Boca Raton, 2010-2011.

[14] S. Sato, K. Tomishige, 105th CATSJ meeting Abstract, 52-2, 71 (2010).

[15] Z. L. Wang, X. Feng, J. Phys. Chem. B, 107, 13563 (2003). [CrossRef]

[16] K. Kaneko, K. Inoke, B. Freitag, A. B. Hungria, P. A. Midgley, T. W. Hansen, J. Zhang, S. Ohara, T. Adschiri, Nano Lett., 7-2, 421 (2007).

[17] P. Bera, K. R. Priolkar, A. Gayen, P. R. Sarode, M. S.
Hegde, S. Emura, R. Kumashiro, V. Jayaram, G. N. Subbanna, Chem. Mater., 15, 2049 (2003). [CrossRef]

[18] N. Ichikawa, S. Sato, R. Takahashi, T. Sodesawa, H. Fujita, T. Atoguchi, A. Shi, J. Catal, 239, 13 (2006). [CrossRef]

[19] O. Pozdnyakova, D. Teschner, A. Wootsch, J. Kröhnert, B. Steinhauer, H. Sauer, L. Toth, F. C. Jentoft, A. KnopGericke, Z. Paál, R. Schlögl, J. Catal, 237, 1 (2006). [CrossRef]

[20] S. Hosokawa, M. Taniguchi, K. Utani, H. Kanai, S. Imamura, Appl. Catal. A, 289, 115 (2005). [CrossRef] 